\title{
Gender Mainstreaming in the Danish Central Administration: \\ (Mis)understandings of the Gendered Impact of Law Proposals
}

\section{By Diana Højlund Madsen \& Lise Rolandsen Agustín}

\begin{abstract}
Gender mainstreaming is the dominant strategy of the Danish national gender equality efforts. However, gender impact assessments have neither been sufficiently integrated in the policy-making processes of the Danish ministries nor in their organisational cultures, and their impact is minor. Drawing on feminist perspectives on institutional development the article focuses on two case studies - the Ministry of Employment and the Ministry of Transport - with two different practices for doing gender equality assessments. It is important to consider the (lack of) political demand for gender equality assessments in order to understand the (negative) development in terms of their number and content; very few gender equality assessments are produced, and those that are tend to hold little or no transformative potential as they show limited recognition of the gendered consequences of the law proposals.
\end{abstract}

\section{KEYWORDS}

Gender mainstreaming, gender equality assessments, institutional development, Denmark

Diana Højlund Madsen has worked extensively on gender mainstreaming in a Danish, European and African context. She holds a PhD on gender mainstremaing processes in Ghana and has been an Assistant Professor at Freia, Center for Gender Research, Aalborg University.

Lise Rolandsen Agustín is Associate Professor at the Department of Culture and Global Studies, Aalborg University. Her research interests include gender equality, intersectionality and diversity in relation to both national and European political contexts. 


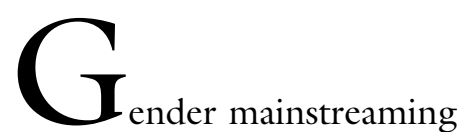

has an international background with the UN Beijing Platform for Action from 1995 and the EU Amsterdam Treaty from 1997. The strategy was adopted and celebrated as the dominant strategy for all future work on gender equality by representatives from governments and women's organisations worldwide. Gender mainstreaming is also the dominant strategy of the Danish national gender equality efforts. The obligation to mainstream was adopted in the Danish Gender Equality Act in $2000 \$ 4$ where it is stated that:

"Public authorities shall within their respective areas of responsibility seek to promote gender equality and incorporate gender equality in all planning and administration".

However, the process of translating the strategy into practice leaves a lot to be desired, and research shows that half of the Danish ministries have not carried out any gender impact assessments despite the obligation to mainstream (Poulsen and Henningsen 2011). Even though several national action plans on gender mainstreaming (2002-2006, 2007-2011) have been drafted and a new strategy on gender mainstreaming was launched in 2013, results have been disappointing and failed to bring about transformation. With the 2013 strategy, the national gender machinery (then Ministry for Children, Gender Equality, Integration and Social Affairs) has rhetorically re-labelled gender mainstreaming 'gender impact assessments' in order to facilitate civil servants' implementation of the strategy in practice. Since gender mainstreaming is difficult to translate into Danish, the intention has been to adapt the term to the Danish context by focusing on gender impact assessments in line with the development in the other Nordic countries, thereby re-launching the strategy.
In a Danish context very little research has been conducted on gender mainstreaming, including research on the reasons for the disappointing results; it is the aim of this article to contribute to filling this knowledge gap. In this sense the article should be seen as knowledge building for both researchers and practitioners. In particular we debate two key questions: First, we analyse the ways in which gender mainstreaming has been implemented in the Danish context as gender impact assessment by analysing ministerial practices in policy-making processes. Next, we turn to the actual gender impact assessments of law proposals in order to examine the understandings of gender mainstreaming and gender (in)equality implicitly or explicitly articulated in the ministerial assessments. In the empirical analysis we focus on two ministries (the Ministry of Employment and the Ministry of Transport) where gender impact assessments have been carried out. However, the ministries are conducting gender impact assessments in very dissimilar ways: In the Ministry of Employment they are carried out on a regular and permanent basis, and in the Ministry of Transport assessments are conducted whenever it is considered relevant. We will shed light on which processes led to the drafting of gender impact assessments within the ministries and which understandings of gender mainstreaming are implied in the gender impact assessments in order to critically examine the ways in which gender mainstreaming is practiced in the Danish central administration.

The aim of the article is to open up the existing 'black box' where the drafting of gender impact assessments plays out in order to gain insight into the gendered power structures influencing these processes. We argue that, in a Danish context, gender mainstreaming or gender impact assessments are dependent on a few feminist-oriented individuals at the state level (femocrats), 
and that gender interests therefore are not institutionalised at the state level (see also Højlund Madsen 2010). As a consequence of this, not only 'top commitment', which traditionally has been emphasised, but also 'ground commitment' at the level of civil servants matter for the implementation of gender mainstreaming and gender impact assessments (Verloo 2001; Roggeband and Verloo 2006) as the individual civil servant has a considerable influence on the translation of the strategy into practice. However, we also find that more or less formalised practices and procedures within the individual ministries influence the quantity and quality of gender impact assessments. Thus, gender mainstreaming and gender equality assessments are related to gendered institutional structures and gendered resistance within the ministries themselves.

First we present different theoretical approaches to gender mainstreaming and reflections on gender and institutional development. Next we introduce the development of gender mainstreaming in Denmark and scrutinise the procedures, organisational cultures and practices in place in the Ministry of Employment and the Ministry of Transport, respectively. Then we analyse and compare the content of the gender impact assessments carried out in the two ministries between 2007 and 2014 in order to interpret their understandings of the gendered consequences of the law proposals. Finally, we summarise the main findings and arguments in the conclusion.

\section{GENDER AND INSTITUTIONAL DEVELOPMENT}

In a European context, gender mainstreaming is defined as:

"The (re)organisation, improvement, development and evaluation of policy processes, so that a gender equality perspective is incorporated in all policies at all levels and at all stages" (Council of Europe, 1998: 15).
The UN definition of gender mainstreaming emphasises that it should be seen as a process and that gender main- streaming is a strategy to achieve another goal - namely gender equality. However, gender mainstreaming has been coined in more theoretical terms by Jahan (1995), Verloo (2001; 2005 ) and Squires (2005). Jahan focuses on gender and development and has defined two different approaches to gender mainstreaming: the 'integrationist' and the 'agenda-setting' approach. The 'integrationist' approach builds gender into existing paradigms with no change of the existing agenda as a result, and the idea is to integrate gender into as many sectors or policy areas as possible - an 'infusion' of gender issues working for incremental changes from within. The 'agenda-setting' approach calls for a transformation of the existing agenda, and recognition of wo- men's voices is seen as fundamental for bringing about change and reorientation of existing priorities or of the mainstream. Jahan herself advocates for the latter approach to gender mainstreaming. The integrationist approach seems to take gender mainstreaming in a bureaucratic / technical direction whereas the agenda-setting approach goes in a more participatory / democratic direction, but it is the former version of gender mainstreaming that is often identified in practice (see, for example, Højlund Madsen 2010).

Verloo $(2001 ; 2005)$ also advocates for 'agenda-setting' in the form of participation of women as decision-makers with the aim of giving them a voice in gender mainstreaming processes. She argues for an extensive concept of participation through consultative processes stating that in order to be transformative, gender mainstreaming should also be a strategy of empowerment and ensure organised space for other actors like women's organisations. However, Verloo also concludes in her analysis of gender policy areas in the EU that women's organisations are not very influential - or at le- 
ast they were not mentioned to a very large extent in the policy documents (Verloo 2007). Squires (2005) lists three mainstreaming strategies - inclusion (the 'integrationist' approach), reversal (the 'agenda-setting' approach) and displacement (the 'transformative' approach) and links these to policies of equal opportunities, positive action and gender mainstreaming, respectively. She argues in favour of displacement; her critique of the other approaches is, on the one hand, that the 'integrationist' approach fails to reflect the needs of the identity groups it is supposed to benefit, and that in the process of accommodating or adapting to the needs of bureaucracies there is a "danger of rhetorical entrapment" (Squires 2005, 374). On the other hand, she puts forward that the 'agenda-setting' approach with the inclusion of women's organisations somewhat "formalise[s] and freeze[s] identities that are under constant change" (Ibid., 375). Other identities than being 'woman' could be equally if not more important. In opposition to this, Squires argues for an intersectional analysis of different categories such as race, ethnicity, class, et cetera (i.e. a focus on diversity mainstreaming) and for the need to destabilise existing gendered categories and understandings. It seems that the three 'projects' differ in terms of being more political or more academic and as regards the main roles of different actors (bureaucracies, women's organisations or academia), with Squires' attempt being the most ambitious, but also the one less likely to be taken on board by bureaucracies due to its complexity. On the basis of the empirical analysis presented below, we will debate which of these approaches apply to the Danish context.

Based on their own experiences as facilitators and researchers on gender mainstreaming in a Flemish ministry, Benschop and Verloo (2006) argue that gender mainstreaming cannot escape the genderedness of an organisation like a ministry. Firstly, during the process of gender mainstream- ing the majority of the participants tried to select the most non-threatening and least controversial aspects of gender mainstreaming and gender equality: they chose 'gender neutrality' as the project goal and narrowed down the gender problematics to be 'about numbers' or representation issues only. Secondly, Verloo accounts for how the civil servants did not want to discuss the analysis, feeling blamed for the potential gender inequalities that it would reveal and therefore meeting the analysis with resistance. The lessons learnt were that gender mainstreaming needs to be framed in very 'gender neutral' terms to relate to the framework of the civil servants just as an element of 'conflict regulation' needs to be present in all gender mainstreaming efforts (Ibid., 30).

Similarly, an article on gender impact assessments in the Netherlands (Roggeband and Verloo 2006) reveals that also in this case gender mainstreaming efforts have been met with resistance. The point of departure is that the actual application of gender impact assessments has been poor, and the authors point out a number of reasons that might explain this: there is an inherent tension in relying on states to provide gender mainstreaming and gender equality, namely that

"even if states are seen as de facto constituents of the reproduction of gender inequality, the same states are seen to have official commitments to gender equality as a political goal" (Ibid., 618).

As such there is a contradiction between the official discourses on gender mainstreaming and gender equality and the gendered outcomes from the state level as well as the gendered ways in which the state operates, even in so-called women or gender friendly states such as the Netherlands and Denmark. In these states the lip service paid to official discourses on gender mainstreaming and gender equality may even prove to be 
counterproductive for civil servants as a picture is painted of countries where gender equality has already been achieved. Roggeband and Verloo have themselves been directly involved in the development of the $\mathrm{Du}$ tch gender impact assessment instrument and point out how different ideas shaped its form as the equality officials from the national gender machinery wished to have a simple checklist that the civil servants could use, whereas the researchers wished to have a more academic instrument needing gender expertise and thereby stressing that gender analysis is a skill to be acquired as it requires a certain amount of knowledge on gender issues. Also, in this case the use of the instrument is somewhat limited because gender experts were being perceived as having "narrow views and goals" and their interventions were perceived as "unwelcome critique" (Ibid., 623). Besides, gender impact assessments were not requested by politicians and were seen by policy makers as "uncomfortable, costly and of little use" (Ibid., 627). Thus, a negative attitude towards the instrument prevailed. This underlines that not only 'top commitment' but also 'ground commitment' to gender mainstreaming and gender equality is needed as civil servants exercise some degree of influence on whether gender impact assessments should be carried out or not.

Another type of explanation for the nonimplementation of gender mainstreaming and the missing gender impact assessments is offered by Hafner-Burton and Pollack (2009); they argue that mainly soft instruments and weak incentives have been used to promote gender mainstreaming and gender equality. According to them a 'hard' gender mainstreaming programme should include

“a) binding provisions entailing b) precise responsibilities and commitments backed by c) strictly enforced positive and negative sanctions for compliance and non-compliance" (Ibid., 123).
In the analysis, we will discuss the extent to which instruments and incentives used in the national efforts on gender mainstreaming have been 'soft' / 'hard' or 'strong' / 'weak'.

\section{GENDER IMPACT ASSESSMENT \\ PRACTICES IN THE DANISH \\ Central Administration}

Since 2000 gender mainstreaming has been part of the Danish gender equality strategy; the Minister of Equality coordinates the efforts of the interministerial gender mainstreaming project whereas each individual ministry is responsible for the execution within their policy area. National action plans in the area were elaborated for the periods 2002-2006 and 2007-2011. In 2013 a new strategy on gender impact assessments was introduced. Every second year ministries must report back to the $\mathrm{Mi}$ nistry of Equality regarding their gender impact assessments. The Ministry defines gender impact assessments as the

"means to include knowledge of women and men's behaviour within a certain area of problem solving with a view to procuring the most effective intervention and improving gender equality" (Ministry for Gender Equality 2013,3$)$.

Civil servants have guidelines from the $\mathrm{Mi}^{-}$ nistry of Gender Equality and access to a website addressing how to conduct gender impact assessments, with examples and tools. In the policy-making process, law proposals are screened according to the guidelines as to their gendered relevance, and civil servants assess what kinds of gendered consequences the law proposal entails, if any. If a gender impact assessment is to be carried out, civil servants should build this on data and statistics in order to determine the gendered effects of the law proposal.

In a Danish context, gender equality assessments are not in high demand political- 
ly speaking; this resonates with the analysis by Roggeband and Verloo (2006) of the Dutch case as referenced above. Gender equality assessments are typically associated with left-wing politics, and questions to the parliamentary committee on gender equality are often asked by the left-wing party the Red-Green Alliance, for example a number of questions posed to the responsible Minister on gender equality assessments in September 2012. In his replies, Manu Sareen, the then Minister for Children, Gender Equality, Integration and Social Affairs, admits that the number of gender equality assessments produced by the ministries is not satisfactory, and that gender equality assessments should be seen as an important tool to identify the gendered consequences of a law proposal. However, in other interventions he states that it is up to the individual ministries or in practice the individual civil servants how they will ensure mainstreaming of gender equality in their work. The Minister argues that gender equality assessments only make up one tool and states that just because a law seems to have differential effects on women and men, it does not necessarily mean that one could or should not adopt it, only that there needs to be a certain level of awareness about it. In addition, he argues that relevance tests should not be made publicly available as they are only the first step in the gender equality assessment and some proposals are rejected because of their technical nature (Answer to question number $5413 / 92012$ for the minister from the Red-Green Alliance. On these grounds we could question the level of commitment from the Ministry for Children, Gender Equality, Integration and Social Affairs itself as they would be expected to defend the usefulness of gender equality assessments and the consequences to be drawn from them rather than the opposite. Similarly, in September 2014, the spokesperson on gender equality from the $\mathrm{Li}^{-}$ beral Party (then in opposition but now the ruling party) stated that they do not have any ambition to 'gender assess' everything (Politiken 2014).

The analysis of the ministerial use of gender impact assessments in the preparatory law work shows that this is indeed limited with the exception of the Ministry of Employment. In the annual reports carried out between 2007 and 2014 only 32\% of the ministries stated to have performed one or several gender impact assessments. At the same time, the gender impact assessments that are carried out have a very limited impact on law proposals as we shall see in the analysis below.

\section{Procedure, Organisational Culture and Practices}

The two cases which have been selected here, i.e. the Ministry of Employment and the Ministry of Transport, show significant differences between the ways in which gender impact assessments are managed in the preparatory law work. In the Ministry of Employment attention to gender is compulsory: law proposals must always be accompanied by a gender impact assessment. The Ministry of Transport follows the basic requirements of the ministerial guidelines by only including gender impact assessments in the law proposals when gender consequences are considered to be significant.

The Ministry of Employment is the pioneer when it comes to gender mainstreaming efforts at ministerial level in the Danish central administration. Internal compulsory standard procedures for the execution of gender impact assessments are implemented, and a systematic monitoring is carried out. In the Ministry of Employment no formalised internal feedback procedures exist in relation to the work on gender impact assessments. Gender impact assessments are perceived as a legal responsibility and as a necessity for carrying out well-executed preparatory law work (i.e. knowledge of the target group). Our document analysis 
(see below) shows that a (short) gender impact assessment is always included in the law proposal and it typically focuses on the gender composition of the target group by making extensive use of gender-divided statistics.

The Ministry of Transport follows the guidelines provided by the Ministry of Finance, i.e., a relevance test is conducted and, if the test is positive, a gender impact assessment is also carried out. The relevance test is not necessarily documented in writing and the content of the gender impact assessment is only included in the law proposal if significant gender consequences are envisaged. Our analysis of law proposals from the Ministry (see below) shows that in the latter case a (brief) gender impact assessment is included in the law proposal; it typically contains information on the gender composition of the target group and its behaviour (in relation to transportation). The gender impact assessments are carried out by the corresponding units and its civil servants with the option of consulting the gender equality representative of the Ministry. This typically only happens in relation to the drafting of the gender impact assessment. Quality assurance of the law proposal and its gender impact assessment is carried out by the legal unit. In the Ministry of Transport gender equality is considered to be an integrated part of the processes and not an add-on; reflections on gender consequences should always be taken into account even though the law proposals of the Ministry rarely are considered to have gendered consequences. In other words, gender equality reflections have to be engraved in the ministerial culture. An internal gender equality network works to ensure this as it addresses gender equality issues within the policy areas of the Ministry and serves as a forum for exchange of information on gender relevant data in the sector, etc. The network is also responsible for informing new employees on the importance of gender equality in the law- making processes. The Ministry's gender equality representative is the coordinator of the network where all the major departments and institutions of the Ministry are represented and responsible for the link between network and civil servants (through communication with the legal unit).

\section{UNDERSTANDINGS AND \\ INTERPRETATIONS OF \\ GENDER EQUALITY AND \\ GENDER MAINSTREAMING}

In this part of the analysis we scrutinise the ways in which gender equality and gender mainstreaming have been framed through an in-depth analysis of all gender impact assessments carried out by the Ministry of Transport and the Ministry of Employment, respectively, between 2007 and 2014. We do so in order to identify the understandings and interpretations inherent in the two ministries and the way in which these understandings may hinder or promote efficient and in-depth gender impact assessments and, consequently, the possibilities for gender equality transformation through gender mainstreaming.

In this period, the Ministry of Transport carried out three gender impact assessments. The first is a law proposal amending the Act on Taxi Services (L118, 2009/ 2010). The proposal concerns surveillance cameras in taxis. It is assessed to benefit women because they will "to a higher extent than men experience surveillance cameras in taxis as reassuring", thus enhancing women's access to the transportation system. The gender impact assessment includes a qualitative target group analysis focusing on the positive gendered effects of the proposal. The other two law proposals from the Ministry of Transport (L134, 2009/2010; L77, 2011/2012) are similar in nature as are their respective gender impact assessments. The proposals concern changing specific infrastructures of the public transportation system by train. The 
gender impact assessments refer to existing studies and data within the area in order to conduct gendered target group analyses. They both state that:

"Studies of transportation habits show that women to a higher degree than men use public transportation"

and then go on to explain that whereas the genre (public transportation by train) caters to women, the type caters to men (more trains per hour and long-distance journeys, respectively). Thus the gender impact assessments conclude that different needs are addressed and that both women's and men's use of public transportation will increase as a consequence of the proposals.

Analysing the gender impact assessments of the Ministry of Employment from 2007 to 2014 , in a total of 130 law proposals, we can identify three key tendencies when it comes to the ways in which the gender impact assessments conclude on the gendered consequences of the respective law proposals: 1) the law proposal is gender neutral; 2 ) gender differences relate to already existing structures; and 3 ) the law proposal is of a technical nature and therefore has no gendered consequences. In the following we will analyse these three tendencies more in-depth.

One fifth of the law proposals analysed from the Ministry of Employment use gender neutrality as the main argument for stating that the law proposal has no gendered consequences, whereas close to half mention gender neutrality in their argumentation. Typically the gender impact assessment would state that:

"The law proposal is gender neutral as regards formulation and intention. It is not estimated to be significant to the opportunities and behaviour of women and men in the labour market".

An example of this logic can be found in the proposal to amend the Act on Benefits in the event of Illness or Childbirth (L68, 2010/2011). The proposal addresses the distribution of expenses between employer and municipality by extending the period in which the employer must hold expenses for the employee's sick leave, thus exempting the municipality of this financial responsibility for a longer period than previously. The proposal is said to "encourage the individual employer to prevent short-term sick leave to a higher extent". The gender impact assessment recognises that "employers will be more hesitant to hire vulnerable unemployed people", and according to the data provided in the assessment women make up the majority of these groups. However, the law proposal includes provisions for particular groups so that there will be full compensation for employers in these cases, and therefore the law proposal is considered to have no gendered consequences. In this case statistical data are used to back up the argument of gender neutrality. In other cases there are no available data and the proposal is instead assessed by the civil servants - without reference to statistical data or analyses - to not be expected to have any gendered consequences, and therefore gender neutrality is used as an argument. This can be considered the 'minimum model': a gender impact assessment is made, but in the briefest and least time-consuming way possible.

Gender neutrality is also used in a less convincing way. This is the case of the gender impact assessment of the proposal to amend the Act on Unemployment Benefits (L222, 2009/2010). The proposal reduces the duration of the period in which unemployed people are entitled to unemployment benefits (from four years to two years). Based on data showing that more women than men have used more than two years of their benefit period (even though they represent a smaller share of the total number of unemployed), the proposal concludes that: "More women than men will 
therefore be affected by the proposal". However, contrary to the expectation of what the purpose of a gender impact assessment is, the law proposal is assessed to be "gender neutral in relation to the target group". This conclusion is based on an argumentation which states that "existing differences or rights" are not affected. The example shows how gender impact assessments will not have any effect if they are based on the logic of gender neutrality due to existing structures; a logic which, by excluding the attention to indirect consequences of the law proposals, is at odds with the ways in which gender mainstreaming is defined in the EU and the UN.

This kind of argumentation is quite common in the gender impact assessments of the Ministry of Employment. The Ministry understands gender impact to be related only to the gender consequences directly caused by the law proposal; thus, almost one third of the law proposals analysed argue that there are no gendered consequences by stating for instance that

"the law proposal is not assessed to influence existing differences or rights. The proposal does not affect the structures that situate men and women differently".

Target group analyses using gender-divided statistics may be employed in this type of gender impact assessments, but regardless of the result of the analysis it is concluded that the differentiated impact of the law proposal is not a consequence of current rules or the law proposal at hand but instead relates to already existing (gendered) structures in the labour market. In other cases the same logic is used, but it is highlighted that the law proposal does not lead to displacements in the state of affairs of gender differences. As an example the gender impact assessment of an act suspending the transport discount for the early retired concludes that more women than men (70\%) make use of the discount; likewise, more women than men $(60 \%)$ make up the early retired. Women will be disproportionately affected by the suspension of the discount. The contradictory logic depicted above, however, prevails in the assessment as it states that:

"The proposal will, nevertheless, not affect the structures that place men and women differently in the labour market".

As a consequence no gendered impact of the law proposal is taken into account.

The structural argument illustrates a basic misunderstanding of the logic of gender impact assessments within the Danish central administration. The assessments are not carried out according to the intentions (Poulsen and Henningsen 2011) when laws applying to the population at large are considered to be gender neutral per se, and 'already existing differences' (i.e. underlying social and economic structures) are exempted and serve as an excuse for not addressing the gendered consequences of a specific law proposal. This interpretation is also engrained in the Ministry of Equality whose guidelines for conducting gender impact assessments state that:

"Gender impact assessments are only to be carried out when it is relevant. In this regard, it should be noted that a law proposal can reflect already existing gender differences. Sometimes these can be amended but other times this is not possible because it would require changes beyond the scope of the law proposal. In such cases it is not the law proposal in question which has consequences for gender equality" (Ministry of Equality 2013, $3)$.

Theoretically, the logic of gender mainstreaming would nevertheless imply that due to underlying structures and differences, policies affect social groups differently and this is what gender impact assessments should address. 
Another fifth of the law proposals presented by the Ministry of Employment between 2007 and 2014 are stated to be of a technical nature and therefore have no gendered consequences. This happens in cases where the law proposals imply a simplification of current rules, for instance, or where they relate to administrative procedures of municipalities, companies or organisations. Indirect consequences (for gendered target groups) are typically not considered, as the 'technical nature' argument seems to justify not taking the gender impact assessment any further. Seldom are considerations as to the potential consequences of the law proposal in the implementation phase addressed.

Other examples of gender impact assessment logics are also found in the material. Some argue that no intended or unintended gender-differentiated consequences follow from the law proposal as it does not aim for differentiated treatment; others refer to the lack of data divided by gender for the purposes of analysing the target groups (meaning that it is not possible to assess and therefore the law proposal is considered to be gender neutral). Some argue that women and men will be affected equally by the law proposal as target group analyses show no gender differences, whereas law proposals which specifically relate to gender equality measures state the positive gendered consequences. A few law proposals on pensions contain analyses of the possible scenarios of outcome analysed from a gender perspective (depicting differences in pensions savings and in public/private pensions given that more women than men only receive public pensions), but include no recommendations, i.e. the analysis does not have any consequences (L40, 2007/ 2208; L168, 2008/2009).

Thus, the analysis demonstrates that the understandings of gender and gender mainstreaming related to the focus on 'gender neutrality' and 'gender differences related to already existing structures' more than anything preserve the status quo and will not result in any transformation of existing unequal gendered structures in Denmark. The narrow focus on gender impact assessments articulated in the recent Danish strategy in the field supposes a diluted and instrumentalised version of gender mainstreaming which deemphasises the focus on power relations and shows a lack of political edge. The transformative potential, which gender mainstreaming in theory holds, is in other words lost in translation.

\section{Concluding Comments}

Gender mainstreaming is not sufficiently integrated in the policy-making processes of the ministries, and its impact on law proposals is minor. It is important to consider the (lack of) demand for the gender equality assessment from the political level to understand the (negative) development in terms of their number and content; very few gender equality assessments are produced, and those that are hold little or no transformative potential. The Ministry of Employment has many gender impact assessments but of varied quality; whereas the Ministry of Transport drafts few gender impact assessments. Across the material there is an underlying implicit resistance towards in-depth assessment practices when it comes to gender impact. Many of the assessments return to the same rationale and the same formulations. This is to some extent logical as time constraints and needs of efficiency in policy-making processes would spur the case officers to rely on previously elaborated documents, thus also adding to the coherence of the way in which gender impact assessments are handled in the Ministry over time. However, it also reflects a certain automatic reaction where the same formulations are used as an easy solution to an inconvenient assignment. This results in misunderstandings and superficial practices which have been reproduced and maintained over time, thus creating a practice whe- 
re references to existing research, for example, or experience from other countries are not included as they are not a part of the culture of gender impact assessment performance within the Ministry. This impedes the development of more in-depth analyses and highlights the need to attend to top commitment and ground commitment simultaneously in order to make progress within this area. Thus, it holds true for both ministries that in-depth gender impact assessments are reached when we move beyond descriptive analyses based solely on statistical information on target group composition and instead combine this information with considerations as to various scenarios of potential impact (i.e. different outcomes of the legislation) and their gendered consequences. Furthermore, gender neutrality is a dominant frame in the analysed material, confirming the point that gender mainstreaming framed as gender neutrality resonates better with the policymaking process and the work procedures of civil servants as well as the kinds of resistance we may find within this framework (Roggeband and Verloo 2006).

The focus on gender impact assessments does not seem to be the right solution to ensure the translation of gender mainstreaming into practice; even this 'integrationist' version of gender mainstreaming is not very successful. Gender mainstreaming or gender impact assessments do not address the underlying gendered structures, and even in the cases where they reinforce existing unequal gendered structures, it is argued that it is not the policy proposal or law in itself which creates these unequal structures. As a result impact assessments become 'business as usual' and Sisyphus work. The Danish case in the Ministry of Transport is characterised by 'soft' instruments like the establishment of networks whereas the Ministry of Employment to some extent uses 'hard' incentives in the form of internal, compulsory standard procedures and a systematic monitoring. The question is, then, how the systematic approach can be improved and / or how the cultural approach can be rooted in institutional procedures. It would potentially be more effective to combine the two models for doing gender impact assessments in the respective ministries. Gender impact assessments should be carried out early in the policy- and law-making processes in relation to all major reforms of laws and policies by qualified staff with a proper understanding of gender and gender mainstreaming and backed by networks with gender mainstreaming experts from inside as well as outside the ministry. Similarly, the different approaches to gender mainstreaming ('integrationist' and 'agenda-setting') should be combined to ensure a fruitful insider-outsider dynamics on gender mainstreaming which may be able to bring about change in the right (gendered) direction. As regards Squires' suggestion to focus on an intersectional approach in mainstreaming efforts, the present situation of gender mainstreaming efforts in Denmark makes this a less than realistic scenario in the near future despite the fact that the recent Danish gender mainstreaming strategy calls for attention to diversity. However, as the new strategy focused largely on the communicative effort of reframing gender mainstreaming as an administrative measure (labelling it gender impact assessment), the focus on diversity also pertains mostly to the need for a reframing of the strategy in order to provide it with new persuasive fuel rather than changing the underlying institutional barriers.

\section{Notes}

1. We wish to thank Julie Holt Pedersen for her assistance in gathering the documents used in the analysis as well as the two anonymous reviewers for their valuable comments and suggestions.

2 . The two cases differ in a number of ways, but most importantly the Ministry of Employment has a longer history of addressing gender equality 
issues than the Ministry of Transport, coupled with the fact that gender and employment is a more well-researched area than gender and transport although some research is available in this area as well.

3. The UN definition reads: "Mainstreaming a gender perspective is the process of assessing the implications for women and men of any planned action, including legislation, policies or programmes, in all areas and at all levels. It is a strategy for making women's as well as men's concerns and experiences an integral dimension of the design, implementation, monitoring and evaluation of policies and programmes in all political, economic and societal spheres so that women and men benefit equally and inequality is not perpetuated. The ultimate goal is to achieve gender equality" (ECOSOC July 1997, Chapter IV).

4. Unless otherwise stated the information on ministerial practices, which is provided in this section, is based on communication with civil servants from the respective ministries in June and July 2016.

\section{BIBLIOGRAPHY}

- Benschop, Y. and Verloo, M. 2006. Sisyphus' Sister: Can Gender Mainstreaming Escape the Genderedness of Organisations? Journal of Gender Studies $15(1)$.

- Council of Europe 1998. Gender Mainstreaming. Conceptual framework, methodology and presentation of good practices. Strasbourg.

- Hafner-Burton, E. and Pollack, M. 2002. Mainstreaming Gender in Global Governance. European Journal of International Relations 8(3).

- Hafner-Burton, E. and Pollack, M. 2009. Mainstreaming Gender in the European Union: Getting the Incentives Right. Comparative European Politics 7 .

- Jahan, R. 1995. The Elusive Agenda - Mainstreaming Women in Development. London: Zed Books.
- Kantola, J. and Squires, J. 2012. From State Feminism to Market Feminism? International Political Science Review 33(4).

- Manicom, L. 2001. Globalising Gender in - or as

- Governance? Questioning the Terms of Local

Translations. Agenda 48.

- Ministry of Equality 2013. Guidelines for gender impact assessments of law proposals [Vejledning til ligestillingsvurdering af lovforslag]. Copenhagen. - Parliament 2012. Question 54 13/19 on gender equality assessments from Red-Green Alliance. - Politiken 2014: Ministries puts gender equality on hold. September 2.

- Poulsen, H and Henningsen, I. 2011. Lov er lov - og lov skal ligestillingsvurderes. Women, Gender \& Research [Kvinder, Køn \& Forskning] 20(2), 52-57.

- Roggeband, C. and Verloo, M. (2006): Evaluating Gender Impact Assessments in the Netherlands (1994-2004): A Political Process Approach. The Policy Press 34(4).

- Squires, J. 2005. Is Mainstreaming Transformative? Theorizing Mainstreaming in the Context of Deliberation. Social Politics - International Studies in Gender, State and Society 12(3).

- United Nations Economic and Social Council (ECOSOC) 1997. Mainstreaming the Gender Perspectives into All Policies and Programmes in the United Nations System. NYC.

- Verloo, M. 2001. Another Velvet Revolution? Gender Mainstreaming and the Politics of Implementation. IWM Working paper No. 5/2001, Vienna.

- Verloo, M. 2005. Displacement and Empowerment: Reflections on the Concept and Practice of the Council of Europe Approach to Gender Mainstreaming and Gender Equality. Social Politics International Studies in Gender, State and Society $12(3)$.

- Verloo, M. 2007. Multiple Meanings of Gender Equality - A Critical Frame Analysis of Gender Policies in Europe. CEU Press. 


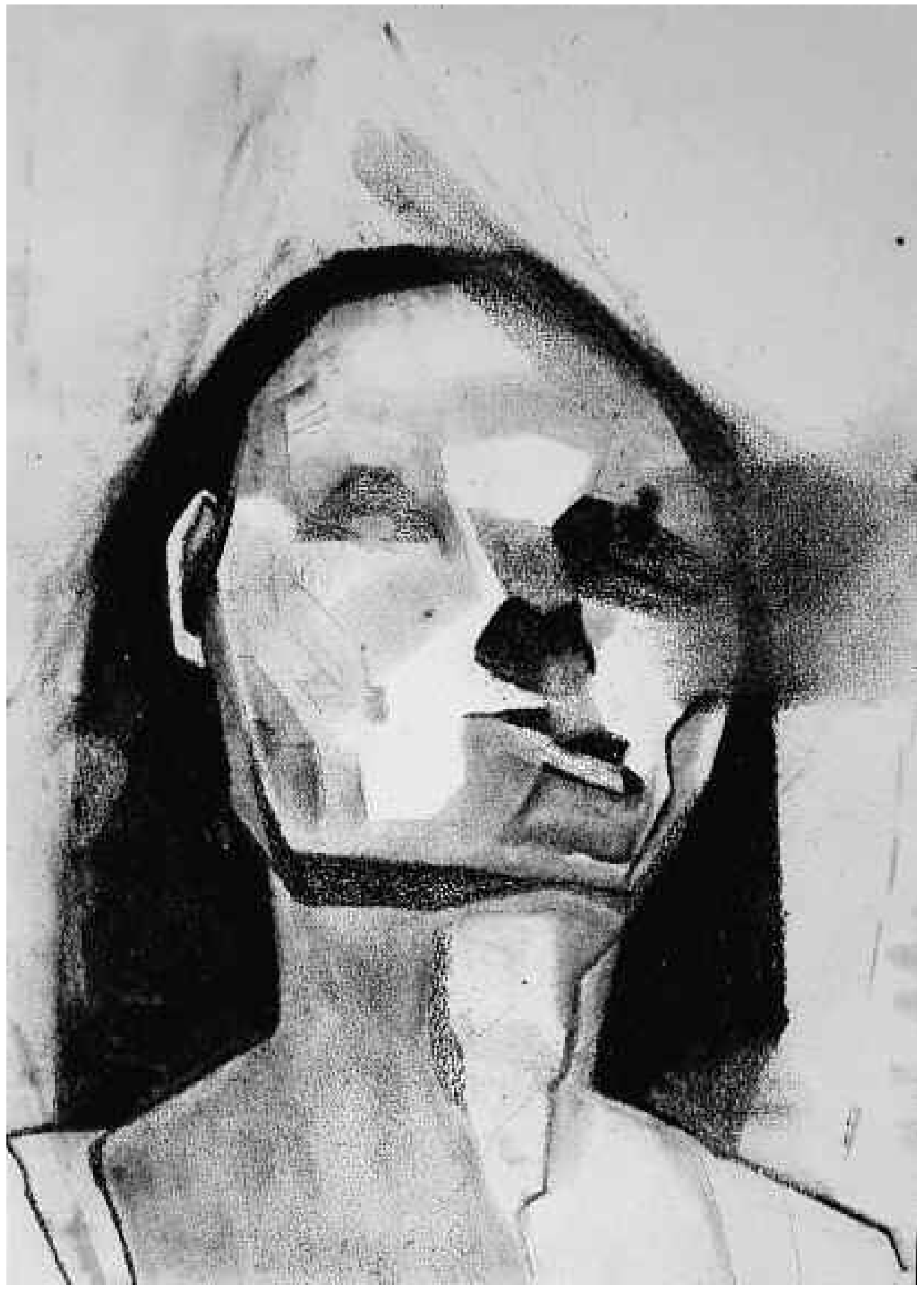

Eva Kragh Petersen: Uden titel, olie på papir, 42x59,4 cm. 